\title{
RevistAleph
}

\section{MEU CONHECIMENTO DE MATURAMA}

Luiz Antonio Botelho Andrade (UFF)

Eu conheci Humberto Maturana no ano de 1982, em Campinas, durante a Sociedade Brasileira para o Progresso da Ciência (SBPC), no Simpósio organizado pelo Dr. Nelson Vaz, então Professor do Departamento de Imunobiologia da Universidade Federal Fluminense (UFF). Do encantamento para com o novo paradigma - Biologia do Conhecer - venho tentando compreender os fundamentos epistemológicos do referido paradigma e até mesmo utilizando os mesmos em diversos textos e contextos de minha vida universitária, na UFF.

Embora eu tenha me doutorado em Imunologia no Instituto Pasteur, no período de 1986 a 1990, por indicação do Professor Nelson Vaz, a quem muito agradeço, a educação é minha outra paixão. Assim, de volta à UFF, depois do doutoramento, mesmo exercendo alguns cargos administrativos, eu nunca deixei de lecionar e de me aprofundar na extensa obra de Maturana. Enquanto Diretor do Instituto de Biologia, participando das acaloradas discussões do Conselho Universitário sobre autonomia universitária, dialogando com a Biologia do Conhecer de Maturana, propusemos uma teoria para conceber a universidade (ANDRADE et al. 2000; 2001) em sua relação de coderiva histórica com a sociedade (ANDRADE et al. 2002). No Instituto de Biologia, criamos o Curso de graduação de Biologia, no ano 2000, no qual, desde então, fiquei responsável pela disciplina de Biologia do Conhecer, ministrada de forma presencial, imersiva e, agora, durante a pandemia do novo coronavírus (Sars-Cov-2), de forma remota, respondendo à necessidade imperiosa de distanciamento social. Enquanto Pró-reitor de Extensão, tive a oportunidade de organizar, junto com o Prof. Leonardo Guelman do IACS, então Diretor do Centro de Artes da UFF, a Agenda Acadêmica de 2005, com o tema Interlatinidades. Dentre os vários eventos realizados durante a Agenda de 2005, eu ressalto dois momentos muito marcantes - a realização de um congresso em homenagem a Paulo Freire, com a participação do poeta Tiago de Mello, e a vinda de Humberto Maturana à Niterói (Figura

1). Na Universidade, Maturana conversou com os dirigentes máximos da Instituição - os Professores Cícero Mauro Fialho Rodrigues e Antonio José Peçanha, reitor e vice-reitor, 


\section{RevistAleph}

respectivamente, e com vários diretores de unidade, conselheiros e estudantes. Dos participantes deste encontro, eu destaco o Prof. Luiz Walter, então presidente da FEC, o Professor Waldeck Carneiro, então Diretor da Faculdade de Educação, o Prof. Emmanuel Andrade, da Escola de Engenharia, e a Professora Célia Linhares, com quem compartilho até hoje muitos sonhos sobre Educação.

Para aprender mais sobre a Biologia do Conhecer, eu fiz um curso de uma semana com Humberto Maturana, no Instituto Matrístico, em Santiago do Chile, em 2006. Nesta época, as aulas eram ministradas pelo próprio Maturana, em um quadro negro convencional, e iniciadas sempre com o rosto de um bonequinho desenhado no canto superior do quadro negro. Ele repetia sempre que o desenho era para chamar a atenção dos estudantes que as suas proposições deveriam ser tomadas como um convite à reflexão e não como verdades incontestes. Retornei ao Instituto Matrístico em mais uma ocasião, para uma colaboração acadêmica, na companhia da Professora Rita de Cassia Vasconcellos, do Departamento de Imunobiologia da UFF, à convite do Professor Nelson Vaz (UFMG).

Mais recentemente, eu me tornei membro do Observatório Internacional de Inclusão, Interculturalidade e Inovação Pedagógica (OIIIPE). No âmbito deste coletivo nos reunimos em uma disciplina aberta, aos sábados, de fevereiro à junho do corrente ano, intitulada "Conversas sobre a Biologia do Conhecer". Com as possibilidades tecnológicas de agora, as "Conversas de sábado", como eram chamadas, alcançaram várias partes do Brasil e do exterior e foram enriquecidas pelos diferentes saberes dos professores que participaram destas conversas, especialmente os Prof. Nelson Vaz (UFMG), Carlos Morthé (Consultor em educação) e José Mendes Fonteles (UFC). Contribuíram também, de forma ocasional, os Professores Jorge MPodozis (Chile) e Beto Vianna (UFS). Algumas das ideias discutidas no Curso estão disponíveis em um dossiê da Revista Helius (VIANNA, ANDRADE e VAZ, 2021). Em 6 de maio do corrente ano, recebemos a triste notícia do falecimento do Professor Humberto Maturana, para quem realizamos um tributo muito emocionante no âmbito de nossas "conversas de sábado". 


\section{RevistAleph}

Consternado com as mais de 500 mil vidas brasileira perdidas, muitas das quais provocadas indiretamente pelo desgoverno, reunimos forças para falar do amor matrístico (em Maturana) que, não sendo sentimentalismo, é concebido como disposição corporal de aceitação do outro, enquanto legítimo outro na convivência (MATURANA, 2001; 2002). Nesta concepção, o amor, enquanto emoção que fundamenta o social e, por conseguinte, a educação, se torna revolucionário nestes tempos de incitação à cultura do ódio, pelo desgoverno.

No contexto das comemorações do Centenário de Nascimento do Patrono da Educação brasileira - Paulo Freire (1921-1997), e do falecimento de Humberto Maturana (19282021), aceitamos articular as epistemologias de ambos - Freire e Maturana - em um capítulo de Livro organizado pelo Prof. Waldeck Carneiro, a ser lançado no mês de setembro do corrente ano.

\section{Referências}

ANDRADE, L. A. B; LONGO, W. P.; PASSOS, E. Autonomia como um modelo explicativo da ontologia da universidade. Revista Universidade e Sociedade, n. 21, p. 73-84, Distrito Federal, 2000.

ANDRADE, L.A.B. \& SILVA, E.P. Universidade e sua relação com o outro: um conceito para extensão universitária. Revista Educação Brasileira, Vol. 23, No 47, p.65 - 79, Distrito Federal, 2001.

ANDRADE, L.A.B.; SILVA, E.P.; LONGO, W. P. \& PASSOS, E. Coderiva: uma história de congruência entre universidade e sociedade. Movimento. Revista da Faculdade de Educação da UFF, Niterói, v.6, p. 58- 89, 2002.

MATURANA, H. Cognição, ciência e vida cotidiana. Editora UFMG, Belo Horizonte, 2001.

MATURANA, H. Emoções e linguagem na educação e na política. Editora UFMG, Belo Horizonte, 2002.

VIANNA, B.; ANDRADE, L.A.B. \& Vaz, N. M. (2021) Ensinar é impossível, e aprender, inevitável: comentários sobre a epistemologia de Humberto Maturana. Revista Helius, v.3, n.2, fasc.2, artigos do Dossiê, 2021. Disponível

em:https://helius.uvanet.br/index.php/helius/article/view/158 


\section{RevistAleph}

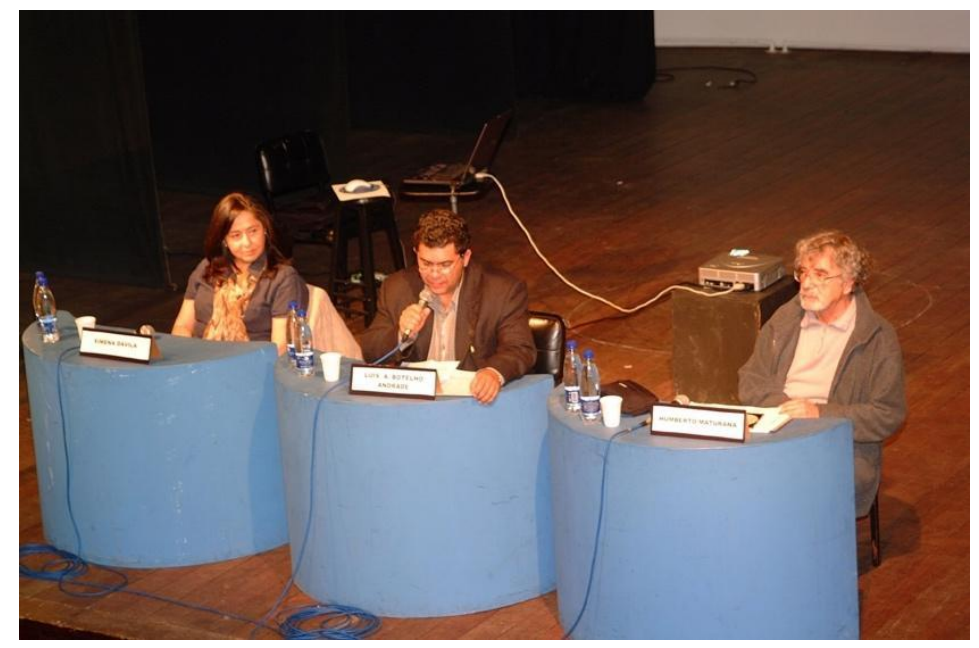

Teatro da UFF - Agenda Acadêmica de 2005 - Interlatinidades

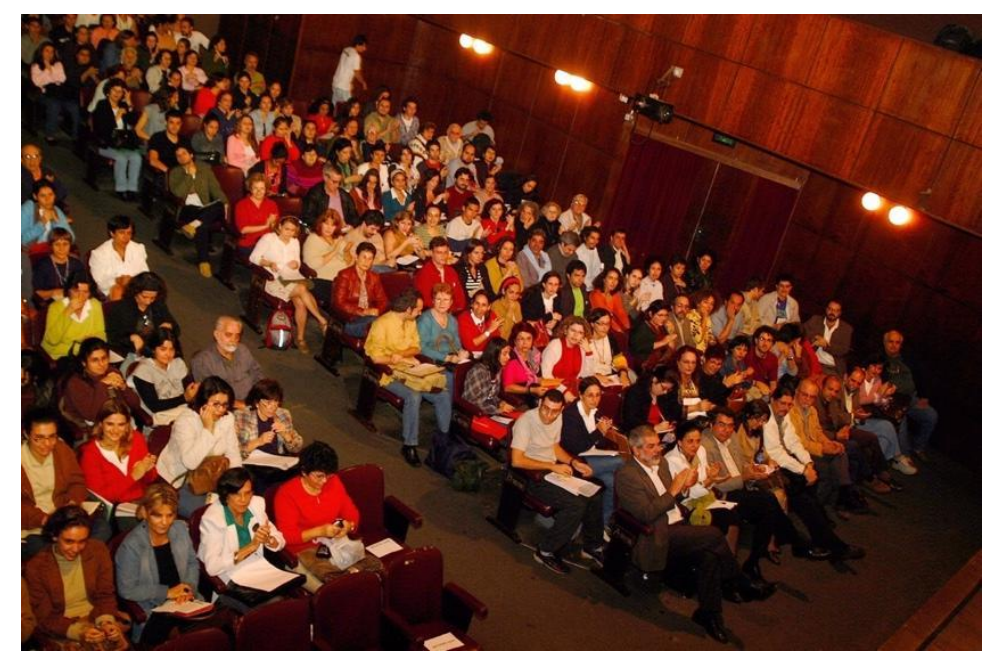

Teatro da UFF - Agenda Acadêmica de 2005 - Interlatinidades 